\title{
Incidence of Postoperative Vomiting and Laryngospasm in Pediatric Anesthesia Using Two Methods: Controlled Ventilation and Spontaneous Respiration
}

\author{
Ali Shahriari, ${ }^{1, *}$ Maryam Khooshideh, ${ }^{2}$ Mahdi Sheikh, ${ }^{3}$ and Mohammad Hassan Heydari ${ }^{4}$ \\ ${ }^{1}$ Department of Anesthesiology and Critical Care, Tehran University of Medical Sciences, Tehran, IR Iran \\ 2 Department of Obstetrics and Gynecology, Tehran University of Medical Sciences, Tehran, IR Iran \\ ${ }^{3}$ Maternal Fetal and Neonatal Research Center, Tehran University of Medical Sciences, Tehran, IR Iran \\ ${ }^{4}$ Department of Anatomy, School of Medicine, Shahid Beheshti University of Medical Sciences, Tehran, IR Iran \\ ${ }^{*}$ Corresponding Author:Ali Shahriari, Department of Anesthesiology and Critical Care, Tehran University of Medical Sciences, Tehran, IRIran. Tel:+98-2122810772, Fax:+98-21-22834332, \\ E-mail:alibenmahdi@yahoo.com
}

Received 2015 January 28; Revised 2015 June 14; Accepted 2015 August 31.

\begin{abstract}
Background: Laryngospasm and postoperative vomiting are serious complications after surgery involving pediatric anesthesia, and these complications may cause morbidity.

Objectives: The objective of this study was to compare the incidences of laryngospasm and vomiting between two groups of children treated with anesthesia. The patients were managed by either controlled ventilation or spontaneous respiration.

Patients and Methods: This prospective clinical study was conducted with 200 children who had underwent elective infraumbilical surgery. The patients were divided to two groups of one-hundred cases, including the control ventilation(CV)and spontaneous respiration (SR) groups. Anesthesia induction and maintenance were the same in all patients. However, in the CV group, atracurium was used as a muscle relaxant to facilitate intubation and surgery.

Results: The incidences of postoperative vomiting, laryngospasm, and excessive secretions were significantly higher in the CVgroup than the $\mathrm{SR}$ group ( $\mathrm{P}=0.001,0.02$ and 0.001 , respectively).

Conclusions: This study demonstrated that the incidences of postoperative vomiting and laryngospasm are significantly higher in patients receiving anesthesia with muscle relaxants and controlled ventilation.
\end{abstract}

Keywords: Vomiting, Laryngospasm, Pediatric Anesthesia, Controlled Ventilation, Spontaneous Respiration

\section{Background}

Postoperative nausea and vomiting (PONV) and laryngospasm are common complications of surgery. These complications occur in 20 to $30 \%$ and 1 to $5 \%$ of patients, respectively (1). The incidence of PONV is dependent on factors such as age, sex, duration of surgery, type of surgery, tobacco use, anesthetics and postoperative opioids. Postoperative nausea and vomiting may complicate patient outcomes and lead to laryngospasm, dehydration, electrolyte imbalance, gastric and esophageal bleeding, pulmonary edema, discharge delay, increased costs, and patient dissatisfaction (2).

Previous studies have reported that using less opioids, replacing opioids with non-steroidal anti-inflammatory drugs, and using less Nitrous Oxide $\left(\mathrm{N}_{2} \mathrm{O}\right)$ or volatile anesthetics can decrease the incidence of $\mathrm{PONV}$ (3).

Most studies examining the incidence of PONV and laryngospasm have employed controlled mechanical ventilation, which is a common method of ventilation during general anesthesia. Spontaneous ventilation was replaced by controlled mechanical ventilation following the introduction of endotracheal tubes and neuromuscular blocking agents in the 1960s. As a result, endotracheal tubes are currently reserved for short duration surgeries.

Controlled-ventilation-based anesthesia has several advantages, such as the tight control of instantaneous ventilation and End-tidal $\mathrm{CO}_{2}\left(\mathrm{EtCO}_{2}\right)$. Neuromuscular blocking agents are usually administered with this method of anesthesia. Neuromuscular blocking agents can facilitate endotracheal intubation and surgery. However, neuromuscular block (residual block) complications occur in the recovery room in 10 to $50 \%$ of cases (4).

Another method of anesthesia induction uses a laryngeal mask airway (LMA) with spontaneous ventilation (5). In contrast to controlled mechanical ventilation, spontaneous ventilation anesthesia has several disadvantages, including the following, reduced tidal volume, minute ventilation, functional residual capacity (FRC), and increased airway resistance and breathing effort (69 ). The complications of spontaneous ventilation include

Copyright (C) 2015, Shiraz University of Medical Sciences. This is an open-access article distributed under the terms of the Creative Commons Attribution-NonCommercial 4.0 International License (http://creativecommons.org/licenses/by-nc/4.0/) which permits copy and redistribute the material just in noncommercial usages, provided the original work is properly cited. 
dislodgement of the endotracheal tube and inadvertent extubation.

Previous studies have shown that spontaneous ventilation is feasible in short pediatric surgeries (10). Furthermore, studies have also shown decreased atelectasis in children (11).

The other benefit of not using a muscle relaxant and neostigmine includes a decreased prevalence of PONV. The goal of our study was to assess the effects of muscle relaxants on PONV.

\section{Objectives}

We designed this study to compare the incidence of PONV in two groups of anesthetized patients due to the importance of reducing PONV and laryngospasm.

\section{Patients and Methods}

This randomized prospective clinical trial was registered by IRCT2012072410385N1 in the Iranian registry of clinical trials (www.irct.ir). The study was conducted after accreditation by the research committee of the department of anesthesiology and critical care of Tehran university of medical sciences.

This study was performed from 2011 to 2012 at the Tehran pediatric medical center hospital. We evaluated 200 patients scheduled for infraumbilical surgery.

The subjects were randomly allocated to each group using a random numbers table. The study was performed after the design was explained and the patients' parents signed an informed consent.

All of the subjects included in the study were aged between two and seven years old and had an ASA class I status. The duration of the surgical procedure was estimated to be less than one hour.

The study exclusion criteria included the following: having upper airway diseases, fever, history of asthma, morbid obesity, cardiovascular diseases, metabolic disorders, renal diseases, and electrolyte imbalances. Additionally, patients with airway irritation, cough, breath holding, bronchospasm, or profuse secretion during intubation were excluded from the study.

The patients received no premedication. One patient group maintained Spontaneous Respiration (SR) and in the other group received controlled ventilation (CV).

After primary monitoring with an Electrocardiogram (ECG), pulse oximetry, and noninvasive blood pressure (NIBP), anesthesia induction was achieved by intravenous administration of $4 \mathrm{mg} / \mathrm{kg}$ thiopental and $1 \mu \mathrm{g} / \mathrm{kg}$ fentanyl.

The patients in the CV group received $0.6 \mathrm{mg} / \mathrm{kg}$ of atracurium, intravenously, and the endotracheal intubation was performed three minutes later. The intubation was performed in the SR group after a stepwise increase in halothane concentration from $1 \%$ to $4 \%$. Sufficient anesthesia was confirmed before the intubation was performed. All patients were ventilated during surgery with $50 \% \mathrm{~N}_{2} \mathrm{O}, 50 \% \mathrm{O}_{2}$ and $1 \%$ - $2 \%$ halothane.
The effects of muscle relaxants were antagonized with $0.04 \mathrm{mg} / \mathrm{kg}$ neostigmine plus $0.02 \mathrm{mg} / \mathrm{kg}$ atropine at the end of the procedure in the CV group. Extubation was performed when the patient was completely awake and could voluntarily move all extremities. The patients were given $10 \mathrm{mg} / \mathrm{kg}$ intravenous paracetamol at the end of surgery. A nurse who was unaware of the method of anesthesia monitored the incidence of vomiting for six hours after extubation.

Patients who had no episodes of vomiting received no medication, and subjects who vomited more than twice received $50 \mu \mathrm{g} / \mathrm{kg}$ of granisetron, intravenously.

The number of post-extubation laryngospasms with peripheral capillary oxygen saturation $\left(\mathrm{SpO}_{2}\right)$ of less than $85 \%$, and the number of profuse secretions, requiring more than one oral suctioning, were recorded.

The probability of vomiting was defined as $30 \%$ in the controlled ventilation group based on previous reports. Our expectation was a $25 \%$ difference in the incidence of vomiting between the two groups with a statistical power of $95 \%$. We used the open epi info software (www.cdc.gov/ epiinfo) and determined that a sample size of 70 patients was needed in each group. We allocated 100 patients to each group to improve the statistical power of the study. Almost the same sample size would be required based on the probability of laryngospasm.

All statistical tests were performed using the SPSS 11 software for Windows. The results are reported as absolute values and mean \pm standard deviation (SD). The continuous variables were analyzed using the Student's T- test. The nominal and ordinal variables were analyzed by the Chi-square test, Fisher's exact test or Mann-Whitney Utest. A P $<0.05$ was considered statistically significant.

\section{Results}

The demographic data for the CV and SR groups are shown in Table 1 . There was no significant difference between the two groups with respect to age, weight or sex. Endotracheal intubation was performed on the first attempt, and no difficult intubations were observed.

We recorded no coughing or breath holding in the CV group. However, eight patients in the SR group experienced coughing and breath-holding and were excluded. Thus, there were 100 cases in the CV group and 92 cases in the SR group.

The mean surgical times in both groups were not significantly different (Table 2). The incidence of vomiting was less in the SR group than the CV group (2\% vs. $16 \%$ ) and was statistically significant $(\mathrm{P}=0.001)$. The incidence of more than one vomiting episode in the SR group was less than the CV group ( $0 \%$ vs. $1 \%$ ), yet was not statistically significant. The incidence of profuse secretions at the end of the procedure in the SR group was less than the CV group (11\% vs. 52\%), and was statistically significant $(\mathrm{P}<0.001)$. The incidence of laryngospasm at the end of the procedure $\left(\mathrm{SpO}_{2}\right.$ $<85 \%$ ) in the SR group was less than the CV group (14\% vs. $27 \%)$. This difference was statistically significant $(\mathrm{P}=0.04)$. 
Shahriari A et al.

\begin{tabular}{|c|c|c|c|}
\hline Variables & CV Group $(n=100)$ & SR Group $(\mathbf{n}=92)$ & P Value \\
\hline Age, y & $61.5 \pm 2.4$ & $12.5 \pm 2.4$ & 0.39 \\
\hline Weight, kg & $71.9 \pm 11.1$ & $85.6 \pm 10.1$ & 0.23 \\
\hline Male/Female & $65 / 35$ & $60 / 32$ & 0.97 \\
\hline Operation duration, $\min$ & $5.1 \pm 12.4$ & $3.4 \pm 13.5$ & 0.08 \\
\hline
\end{tabular}

abbreviations: CV, Control ventilation; SR, Spontaneous respiration.

${ }^{\mathrm{b}}$ Data are presented as mean \pm SD.

Table 2. The Incidence of Adverse Effects in the Two Groups ${ }^{\mathrm{a}, \mathrm{b}}$

\begin{tabular}{lccccc}
\hline & CV Group $(\mathbf{n}=\mathbf{1 0 0})$ & SR Group $(\mathbf{n}=\mathbf{9 2})$ & OR & 95\% CI & P Value \\
\hline Vomiting once & $16(16)$ & $2(2)$ & 8.57 & $1.91-38.41$ & $0.001^{\mathrm{C}}$ \\
Vomiting more than once & $1(1)$ & $0(0)$ & - & - & 0.33 \\
Massive Secretion & $52(52)$ & $11(12)$ & 7.97 & $3.79-16.75$ & $<0.001^{\mathrm{C}}$ \\
Laryngospasm & $27(27)$ & $14(15)$ & 2.06 & $1-4.23$ & $0.04^{\mathrm{C}}$ \\
\hline
\end{tabular}

a Abbreviations: CV, Control ventilation; OR, Odds ratio; SR, Spontaneous respiration; 95\% CI, 95\% Confidence interval.

${ }^{b}$ Data are presented as No. (\%).

${ }^{\mathrm{C}}$ P values less than 0.05 were considered significant.

\section{Discussion}

Several investigators have reported twice the incidence of PONV in pediatric cases compared with adults undergoing surgery with anesthesia (12).

Our study results indicate that the incidence of postoperative vomiting with spontaneous respiration and endotracheal intubation is less than the incidence with endotracheal controlled mechanical ventilation.

There have been several studies comparing spontaneous respiration in adults and pediatric patients. Most studies of PONV have assessed factors such as premedication with antiemetic agents or anesthesia. We found no studies evaluating the incidence of nausea and vomiting based on the type of ventilation during anesthesia.

The use of narcotics, type of surgery, history of difficult intubation, and administration of muscle relaxants have all been postulated to increase the incidence of laryngospasm and postoperative nausea and vomiting (13).

In 2009, Sinha and colleagues studied 90 children aged two to six months old with signs and symptoms of upper airway infection, who were scheduled for infraumbilical surgery. The study compared spontaneous ventilation with controlled mechanical ventilation. All patients in both groups received ProSeal LMA. Sevoflurane, $\mathrm{N}_{2} \mathrm{O}$, and $\mathrm{O}_{2}$ were delivered for the maintenance of anesthesia, and no muscle relaxant was used. There was more coughing, breath holding, laryngospasm, bronchospasm, and pharyngeal secretion in the spontaneous breathing group than the controlled mechanical ventilation group (14).

The incidence of vomiting in the spontaneous ventilation group was reduced in our study. In contrast to the prior study, the incidence of pharyngeal secretions, vomiting, and laryngospasm in our spontaneous respiration group was less than in the controlled ventilation group. However, cough and breath holding were not assessed in our study.

The main distinction of our study compared with the former study was the use of muscle relaxant in the controlled ventilation group. Additionally, we excluded patients with upper respiratory infections from our study. All patients in the prior study had signs and symptoms of upper airway infection.

It should be noted that the incidences of some complications, such as coughing, breath holding, laryngospasm, bronchospasm and volume of secretions, are greater than normal in patients with upper respiratory infection. The incidence of these complications was less in our study compared with the study of Sinha and colleagues (14).

Muscle relaxants are administered and at the end of the procedure in controlled mechanical ventilation. The drugs are antagonized with neostigmine and atropine. These medications are known to increase nausea and vomiting (5).

According to the results of these studies, withholding muscle relaxants may reduce the risk of PONV after anesthesia.

There are several different ideas concerning the effects of neostigmine on PONV. Several investigators have hypothesized that neostigmine does not increase the incidence of PONV $(15,16)$.

In their meta-analysis, Tramer and Fuchs-Buder concluded that doses of neostigmine greater than $2.5 \mathrm{mg}$ increased the incidence of PONV (17).

Lovstad et al. in 2001 evaluated 90 healthy females 
scheduled for gynecologic laparoscopy. The patients were randomized to two groups. Following a 75\% decline in muscle relaxant effect at the end of surgery, $0.5-1 \mu \mathrm{g} /$ $\mathrm{kg}$ neostigmine and $10 \mu \mathrm{g} / \mathrm{kg}$ glycopyrrolate were administered. The placebo group received normal saline. In the group receiving muscle relaxant reversal, the prevalence of nausea and vomiting in the first six hours after surgery was $30 \%$ versus $11 \%$ in the placebo group (18).

Rose et al. reported that in pediatric anesthesia, the coadministration of atropine and neostigmine decreased vomiting shortly after surgery. However, if the patients were followed for a longer period, neostigmine caused more vomiting (19).

There are controversies regarding the effect of neostigmine on PONV. We did not use multiple doses of muscle relaxants in our study. Thus, the low frequency of PONV in the SR group is related to not using neostigmine in this group. Additionally, low secretion in the SR group is likely due to not using neostigmine in this group.

It is known that profuse secretions at the end of a procedure are related to an increased incidence of laryngospasm, and the results of our study confirm this claim. In our study, laryngospasm was reduced in the SR group.

Our results showed reduced vomiting and laryngospasm in pediatric infraumbilical surgeries using spontaneous ventilation and endotracheal intubation less than one hour in duration.

One hypothesis is that neostigmine causes secretions that cause airway irritation and laryngospasm.

Another explanation is that controlled ventilation has a greater potential for gaseous distention of the stomach after administration of muscle relaxants and prior to intubation, which may cause a greater incidence of vomiting.

One of the study limitations was the inability to measure the volume of secretions and stomach pressure in these patients. Another limitation was the inability to accurately measure nausea in children.

We recommend larger studies to compare the incidence of PONV in spontaneous respiration and controlled mechanical ventilation by omitting confounding factors such as neostigmine. Sugammadex may be an alternative medication because it avoids the need for neostigmine and reverses muscle relaxation at the end of surgery.

\section{Acknowledgments}

This article was published in the journal of Gorgan university of medical sciences in the Persian language and permission to publish in English has been obtained. We thank our colleagues at the Children medical center hospital operating room.

\section{Footnote}

Authors' Contribution:Study concept and design: Ali Shahriari and Maryam Khooshideh; acquisition of data: Ali Shahriari, Maryam Khooshideh and Mohammad Has- san Heydari; analysis and interpretation of data: Ali Shahriari and Mahdi Sheikh; drafting of the manuscript: Ali Shahriari, Maryam Khooshideh and Mohammad Hassan Heydari; critical revision of the manuscript for important intellectual content: Ali Shahriari and Mahdi Sheikh; statistical analysis: Ali Shahriari and Sheikh; administrative, technical, and material support: Ali Shahriari and Mohammad Hassan Heydari; study supervision: Ali Shahriari.

\section{References}

1. Gan TJ, Meyer T, Apfel CC, Chung F, Davis PJ, Eubanks S, et al. Consensus guidelines for managing postoperative nausea and vomiting. Anesth Analg. 2003;97(1):62-71. [PubMed:12818945]

2. Ali S. Reduced incidence of laryngospasm with remifentanilmidazolam anaesthesia compared to halothane-fentanyl. J Pak Med Assoc. 2008;58(3):111-4. [PubMed:18517112]

3. Kovac AL. Prevention and treatment of postoperative nausea and vomiting. Drugs. 2000;59(2):213-43. [PubMed:10730546]

4. Apfel CC, Kranke P, Katz MH, Goepfert C, Papenfuss T, Rauch S, et al. Volatile anaesthetics may be the main cause of early but not delayed postoperative vomiting: a randomized controlled trial of factorial design. Br J Anaesth. 2002;88(5):659-68. [PubMed: 12067003]

5. Butterly A, Bittner EA, George E, Sandberg WS, Eikermann M, Schmidt U. Postoperative residual curarization from intermediate-acting neuromuscular blocking agents delays recovery room discharge. BrJAnaesth. 2010;105(3):304-9. doi: 10.1093/bja/aeq157. [PubMed: 20576632]

6. Goldmann K, Roettger C, Wulf $\mathrm{H}$. Use of the ProSeal laryngeal mask airway for pressure-controlled ventilation with and without positive end-expiratory pressure in paediatric patients: randomized, controlled study. BrJAnaesth.2005;95(6):831-4. doi: 10.1093/bja/aei246. [PubMed: 16199419]

7. Bell GT, McEwen JP, Beaton SJ, Young D. Comparison of work of breathing using drawover and continuous flow anaesthetic breathing systems in children. Anaesthesia. 2007;62(4):359-63. doi:10.1111/j.1365-2044.2007.04982.x. [PubMed: 17381572]

8. Keidan I, Fine GF, Kagawa T, Schneck FX, Motoyama EK. Work of breathing during spontaneous ventilation in anesthetized children: a comparative study among the face mask, laryngeal mask airway and endotracheal tube. Anesth Analg. 2000;91(6):1381-8. [PubMed: 11093984]

9. Kopman AF. Neuromuscular monitoring: old issues, new controversies. J Crit Care. 2009;24(1):11-20. doi: 10.1016/j. jcrc.2008.02.008. [PubMed:19272534]

10. Palomero Rodriguez MA, Sanabria Carretero P, Martinez Schmickrath M, Laporta Baez Y, Garcia Fernandez J. Nasopharyngeal Mapleson D CPAP system for sedation in children during magnetic resonance imaging study. Paediatr Anaesth. 2010;20(5):472-4. doi:10.1111/j.1460-9592.2010.03264.x. [PubMed: 20519011]

11. Lutterbey G, Wattjes MP, Doerr D, Fischer NJ, Gieseke J, Schild HH. Atelectasis in children undergoing either propofol infusion or positive pressure ventilation anesthesia for magnetic resonance imaging. Paediatr Anaesth. 2007;17(2):121-5. doi: 10.1111/j.14609592.2006.02045.x. [PubMed:17238882]

12. Kovac AL. Management of postoperative nausea and vomiting in children. Paediatr Drugs. 2007;9(1):47-69. [PubMed: 17291136]

13. Khalil SN, Matuszczak ME, Maposa D, Bolos ME, Lingadevaru HS, Chuang AZ. Presurgical fentanyl vs caudal block and the incidence of adverse respiratory events in children after orchidopexy. Paediatr Anaesth. 2009;19(12):1220-5. doi: 10.1111/j.14609592.2009.03164.x. [PubMed: 20017866]

14. Sinha A, Sharma B, Sood J. ProSeal laryngeal mask airway in in fants and toddlers with upper respiratory tract infections: a randomized control trial of spontaneous vs pressure control ventilation. Middle East J Anaesthesiol. 2009;20(3):437-42. [PubMed: 19950740]

15. Grabowska-Gawel A, Porzych K, Piskunowicz G. [Risk factors and 
frequency of postoperative nausea and vomiting in patients operated under general anesthesia]. Przegl Lek. 2006;63(2):72-6. [PubMed:16969906]

16. Gan TJ. Risk factors for postoperative nausea and vomiting. Anesth Analg. 2006;102(6):1884-98. doi: 10.1213/01. ANE.0000219597.16143.4D. [PubMed:16717343]

17. Tramer MR, Fuchs-Buder T. Omitting antagonism of neuromuscular block: effect on postoperative nausea and vomiting and risk of residual paralysis. A systematic review. Br J Anaesth. 1999;82(3):379-86. [PubMed:10434820]

18. Lovstad RZ, Thagaard KS, Berner NS, Raeder JC. Neostigmine 50 microg $\operatorname{kg}(-1)$ with glycopyrrolate increases postoperative nausea in women after laparoscopic gynaecological surgery. Acta Anaesthesiol Scand. 2001;45(4):495-500. [PubMed:11300390]

19. Rose JB, Watcha MF. Postoperative nausea and vomiting in paediatric patients. Br JAnaesth.1999;83(1):104-17. [PubMed:10616338] 